\section{THU0224 CELECOXIB DECREASED DYSPEPSIA IN OSTEOARTHRITIS AND RHEUMATOID ARTHRITIS PATIENTS: SEVERITY OF DYSPEPSIA ASSESSMENT (SODA) RESULTS FROM THE ? CELECOXIB LONG-TERM ARTHRITIS SAFETY STUDY? (CLASS 2), A RANDOMISED TRIAL COMPARING CELECOXIB AND DICLOFENAC}

${ }^{1} \mathrm{JL}$ Goldstein, ${ }^{2} \mathrm{BM}$ Pena, ${ }^{3} \mathrm{D}$ Dedhiya, ${ }^{4} \mathrm{LS}$ Simon. ${ }^{1}$ Department of Medicine, University of Illinois at Chicago, Chicago, USA; ${ }^{2}$ Research and Development, Pfizer, Inc., New York, USA; ${ }^{3}$ Research and Development, Pharmacia Corporation, Skokie, USA; ${ }^{4}$ Department of Medicine, Beth Israel Deaconess Medical Center, Boston, USA

\subsection{6/annrheumdis-2001.756}

Background Dyspepsia associated with NSAIDs is a cost-driver in the clinical management of arthritis patients and leads to discontinuation of medications.

Objectives To assess the impact of dyspepsia in arthritis patients randomised to celecoxib (C) or diclofenac (D) using SODA.

Methods As part of the double-blind, randomised CLASS trial, SODA (previously validated in dyspepsia patients) was administered at baseline and Weeks 4, 13, 26, and 52 (final visit) to $1997 \mathrm{C}$ patients (400 mg BID, $4 \mathrm{x}$ the OA dose) and $1996 \mathrm{D}$ patients (75 mg BID). Patients with $>=1$ response missing at baseline were excluded, leaving $1791 \mathrm{C}$ and $1816 \mathrm{D}$ patients in the modified ITT (M-ITT) group. SODA has three subscales: pain intensity (6 items characterising the abdominal pain associated with dyspepsia, ranging from 2 to 47); nonpain symptoms (7 items describing the impact of dyspeptic symptoms on daily living activities, ranging from 7 to 35); and satisfaction (4 items describing satisfaction with dyspepsia $\mathrm{Rx}$ ). Lower SODA scores are better.

Results SODA change scores were moderately correlated with number of dyspepsia adverse events and increased with dyspepsia adverse event severity levels (none, mild, moderate, severe) and dyspepsia withdrawal status, irrespective of treatment. An M-ITT analysis with last observation carried forward showed that both groups were equivalent at baseline. Patients receiving $\mathrm{C}$ had lower pain intensity at all follow-up time points, ranging from 12.3 vs 14.5 at Week 4 to 12.6 vs 14.2 at Week 52 (p < 0.001 at all time points). Patients receiving $\mathrm{C}$ were more satisfied at all follow-up time points, ranging from 6.0 vs 6.7 at Week 4 to 6.3 vs 6.9 at Week 52 (p $<0.001$ for all time points). Patients receiving $C$ had fewer nonpain symptoms at Week 4 (12.0 vs 12.4, $\mathrm{p}<0.003$ ) and showed a trend toward fewer nonpain symptoms at subsequent time points. Self-reported dyspepsia was lower with C $(16.5 \%$ vs $19.5 \%, \mathrm{p}<0.05)$. Similarly, GI-driven $\mathrm{AE}$ withdrawal rates were significantly lower for $\mathrm{C}$ than $\mathrm{D}$ at Week $52(12.2 \%$ vs $16.6 \%, \mathrm{p}<0.05)$.

Conclusion Celecoxib patients had less pain intensity and were more satisfied than diclofenac patients, as measured by SODA. These results parallel self-reported dyspepsia and GI-driven withdrawal rates in the study.

Sponsored by Pharmacia Corporation and Pfizer, Inc.

\section{THU0225 COMPLEMENTARY MEDICINE IN RHEUMATIC DISEASES}

${ }^{1}$ SK Chow, ${ }^{1} \mathrm{SS}$ Yeap, ${ }^{1} \mathrm{E}$ Goh, ${ }^{2} \mathrm{~K}$ Veerapen, ${ }^{2} \mathrm{~K}$ Lim. ${ }^{1}$ Department of Medicine, University of Malaya; ${ }^{2}$ Department of Rheumatology, Sunway Medical Center, Kuala Lumpur, Malaysia

10.1136/annrheumdis-2001.757

Background Traditional medicine is widely practised in our country due to the ethnic diversity of this country. It is estimated to account for more than $50 \%$ of our local practice. This study is to assess the usage of traditional medicine among patients who have rheumatological problems.

Objectives To determine the incidence of traditional medicine usage as a form of complementary therapy in a cohort of Malaysian rheumatology patients.

Methods A prospective survey by using a standard questionnaire; the questionnaire was translated into 3 languages and was validated. The survey was conducted in December 2000 in the rheumatology clinic of the University of Malaya and Sunway Medical Centre. Patients who have rheumatological problem were interviewed after obtained verbal consent. Patients' demographic data, monthly income, educational status, diagnosis, duration of disease and the usage of food supplements and traditional medicine were surveyed.

Results A total of 141 patients were interviewed. The mean age of the patients was 48.9 and the female: male ratio was $3: 1$. Racial breakdown was as follows: Malay $=23 \%$, Chinese $=$ $43 \%$, Indian $=31 \%$ and others $=3 \% .20 \%$ of the patients received primary education, $50 \%$ and $23 \%$ had education up to secondary and tertiary level respectively; however $7 \%$ had no formal education. $55 \%$ of the patients had monthly income of $<$ RM1000 (US\$250). 12\% had duration of disease of less than 1 year and $30 \%$ had more than 10 years' disease. 54\% of the patients had Rheumatoid arthritis, 7\% had osteoarthritis. 69\% admitted consuming food supplements; vitamin C and B were the most common food supplement. 35\% used traditional medicine and $69 \%$ used 2 or more type of traditional medicine at any one time for more than 2 months. $25 \%$ spent more than RM 100(US\$25) for their traditional treatment. The most common reason for consuming traditional medicine as complementary medicine was the combination of both western and traditional treatment was thought to be more effective. There was no statistical significance between monthly income $(\mathrm{P}=$ $0.32)$ and duration of disease $(p=0.48)$ as to the usage of complementary therapy.

Conclusion $35 \%$ of the 141 patients used traditional medicine as a form of complementary medicine; $69 \%$ used two or more types of traditional medicine for more than 2 months.

$69 \%$ of them consumed food supplements and vitamin C and B was the most common food supplements.

\section{THU0226 AMYOTROPHIC LATERAL SCLEROSIS (ALS): A TRAP FOR THE RHEUMATOLOGIST}

${ }^{1} \mathrm{P}$ Goupille, ${ }^{1} \mathrm{~S}$ Bouillon, ${ }^{2} \mathrm{P}$ Corcia, ${ }^{1} \mathrm{~J}$ Brunais-Besse, ${ }^{1} \mathrm{~S}$ Quennesson, ${ }^{1} \mathrm{JP}$ Valat. ${ }^{1}$ Rheumatology, CHU, Trousseau Hospital; ${ }^{2}$ Neurology, CHU, Bretonneau Hospital, Tours, France

10.1136/annrheumdis-2001.758

Background ALS is a degeneration of the central and peripheral motoneurons in the bulbar and spinal areas; its mean duration is 36 months (deaths, respiratory disorders). The incidence is $2-5$ cases $/ 100$ 000. Two clinical features are observed: spinal with motor defect of the limbs, bulbar with swallowing disorders.

Objectives To report 6 cases of ALS, observed in a Department of Rheumatology in a University hospital, hospitalised in 1999 for chronic painful syndromes.

Methods Description of: demographic data (age, sex), rheumatologic features (sciatica, cruralgia, painful limb, fatigue on walking.. .), clinical signs, results of explorations, course of the disease and treatment.

Results 